\title{
Growth Inhibitory Property of Pentagamavunone-0 (PGV-0) on 4T1 Cells under Stress Condition: 2D and 3D Culture Model
}

\author{
Haruma Anggraini Muflikhasari ${ }^{1,2}$, Riris Istighfari Jenie ${ }^{2,3}$, Ratna Asmah Susidarti ${ }^{2,3}$, \\ Edy Meiyanto ${ }^{2,3^{*}}$ \\ ${ }^{1}$ Master Student of Biotechnology Program, Graduate School, Universitas Gadjah Mada, Indonesia \\ ${ }^{2}$ Cancer Chemoprevention Research Center, Faculty of Pharmacy, Universitas Gadjah Mada, Indonesia \\ ${ }^{3}$ Department of Pharmaceutical Chemistry, Faculty of Pharmacy, Universitas Gadjah Mada, Indonesia
}

\begin{abstract}
Pentagamavunone-0 (PGV-0), one of the curcumin analogue, is reported to have a cytotoxic effect on various cancer cells. This study aimed to explore the growth inhibitory effects of PGV-0 towards highly-metastatic breast cancer, 4T1 cells under stress condition covering 2D and 3D spheroid cytotoxic, anti-migration, and down-regulation of metalloproteinase-9 (MMP-9). PGV-0 showed cytotoxic activity on 2D and 3D 4T1 cells with $\mathrm{IC}_{50}$ value of $49 \mu \mathrm{M}$ and $26 \mu \mathrm{M}$, respectively. In addition, PGV-0 performed antimigratory effect. The single treatment $25 \mu \mathrm{M}$ PGV-0 and $50 \mu \mathrm{M}$ showed inhibitory effect on cell migration by $54 \%$ and $51 \%$ respectively. Whilst, the combination of PGV-0 at the concentration of $25 \mu \mathrm{M}$ and $50 \mu \mathrm{M}$ with doxorubicin significantly inhibited cell migration by $41 \%$ and $38 \%$, respectively. The gelatin zymography assay showed that PGV-0 downregulated MMP-9 expression both in a single treatment and combination with doxorubicin. In conclusion, PGV-0 is potential to be developed as anti-tumorigenesis agent on highlymetastatic breast cancers.
\end{abstract}

Keywords: Pentagamavunone-0 (PGV-0), anti-migration, MMP-9, 4T1 cells, spheroid

\section{INTRODUCTION}

Cancer metastasis is closely to the cellular stress response against the limited growth support of the microenvironment. Reactive oxygen species (ROS) have been shown to promote metastasis in various cancer cell through the molecular signalling and modulate structural changes in tumor cells called invadopodia (Glasauer and Chandel, 2014; Courtneidge, 2012). Increased intracellular ROS levels over the threshold are known to be toxic to cancer cells and potentially induces cell death (Glasauer and Chandel, 2014; Larasati, et al., 2018).
The imbalance situation of ROS level is the key point to be the target of cytotoxic agents. This study is focused on the modulation of stress response of cancer cells against ROS generation that may play a role in anti-metastatic and growth-inhibitory properties of anticancer agent (Courtneidge, 2012; Kleiner Jr and Stetler-Stevenson, 1993).

Submitted: August 8, 2019

Revised: October 29, 2019

Accepted: October 29, 2019

*Corresponding author: edy_meiyanto@ugm.ac.id 
Pentagamavunone-1 (PGV-1) is one of the analog curcumin can target enzymes that play a role in ROS metabolism. A recent study showed that PGV-1 could increase ROS level and modulate cell cycle arrest at G2/M phase on 4T1 cells. In addition, PGV-1 performs anti-migratory effect through decrease metalloproteinase-9 (MMP-9) better than curcumin (Meiyanto, et al., 2019). Pentagamavunon-0 (PGV-0) has a similar structure to PGV-1, has been widely reported to have anticancer activity in various monolayer cancer cells (Meiyanto, et al., 2003; Meiyanto, et al., 2014; Hermawan, et al., 2011; Ikawati and Septisetyani, 2018). In addition, PGV-0 has a specific cytotoxic mechanism based on the type of cancer cells allow PGV-0 interesting to be explored further about its potential as an anti-metastatic agent. Therefore, to study the mechanism of tumorigenesis inhibition of PGV-0 needs to be proven with 2D and 3D cell culture models that are represented as cellular stress.

The highly-metastatic breast cancer, 4T1 cells, is suitable for exploring new anti-tumorigenesis agents targeting on cell growth and metastasis. The three-dimensional (3D) cancer cell model or commonly known as spheroid culture, is reported to have a micro-environmental stress condition that is almost the same as cancer cells in vivo. Spheroid has three critical zones, namely the outer zone (proliferative zone), the middle zone (quiescent zone), and the deepest zone (necrotic zone). Inward, cellular stress condition is higher, including ROS level (Cui, et al., 2017; Nunes, et al., 2019). The outer most spheroid zone is more easily affected by exposure of a chemopreventive or chemotherapy agent. The cellular stress condition was used by researchers to study the cytotoxic effects of PGV-0 on 4T1 spheroid. Previous study mentioned that curcumin could trigger dissociation and apoptosis in spheroid. Therefore, curcumin analogue PGV-0 is also expected can inhibit the tumorigenesis of cancer spheroid.

To explore the anti-metastatic potential of PGV-0, in this study we used the two-dimensional (2D) 4T1 cells were grown by exposing cellular stress. Doxorubicin and serum starvation are cel- lular stressors to induce cell migration and elevate MMP-9 expression. Curcumin reported to inhibit migration and invasion of various cancer cells. As a curcumin analogue, PGV-0 predicted show the same potential in inhibiting metastasis. Therefore, this study also investigates the possibility of PGV-0 in inhibiting cell migration and suppressing MMP-9 expression on 4T1 cells. These findings will be essential as the basic exploration in clinical application for highly-metastatic breast cancer.

\section{MATERIALS AND METDHOD}

\section{Materials}

PGV-0 and Curcumin (HPLC purity grade) was obtained from Curcumin Research Center (CRC) Faculty of Pharmacy, Universitas Gadjah Mada. The stock solution of PGV-0 was made by dissolving it in dimethylsulfoxide (DMSO) (DMSO 99.5\% pro GC, Sigma Aldrich, Darmstadt Germany). Doxorubicin hydrochloride injection (2 $\mathrm{mg} / \mathrm{mL}$ ) was purchased from Pharmachemie B.V (Swensweg, HaaerlemHolland, Netherlands).

\section{Cell culture}

4T1 triple-negative breast cancer and Vero cells were obtained from Prof. Masashi Kawaichi, M.D., Ph.D. (Nara Institute of Science and Technology, NAIST, Nara, Japan). 3T3-L1 cells were obtained from Dr.med. Muhammad Hasan Bashari, dr., M.Kes. (Universitas Padjadjaran, Bandung, Indonesia). The cells were maintained in Dulbecco's Modified Eagles Medium (DMEM) high glucose (Gibco, New York, USA) with 10\% fetal bovine serum (FBS) (Sigma, St. Leuis, USA), HEPES, sodium bicarbonate, $1 \% \mathrm{v} / \mathrm{v} 1000 \mathrm{U} / \mathrm{mL}$ penicillin-1000 U/ $\mathrm{mL}$ of streptomycin (Gibco, New York, USA) and cultured in the $\mathrm{CO}_{2}$ incubator at $37^{\circ} \mathrm{C}$. Cell were harvested from culture dish with trypsin-EDTA $0.025 \%$ (Gibco, New York, USA) at 80\% confluence level.

\section{Monolayer MTT Cell Viability Assay}

4T1 cells were seeded into each well of a 96-well plate (Iwaki, Shizuoka Prefecture Haibara- 
gun, Japan) at the density of $2.5 \times 10^{3}$ cells/well. Cells were treated with various concentration of PGV-0, curcumin, and doxorubicin. After $24 \mathrm{~h}$ of incubation, cell viability was assesed by MTT assay (Thermo Fisher, Invitrogen, New York, USA) according to the manufacture's instructions (Mosmann, 1983).

\section{Spheroid Formation and MTT Cell Viability Assay}

Homogeneous breast cancer spheroid were generated according previous study. Briefly, 4T1 cells were seeded on agarose-coated (Sigma Aldrich, Steinheim, Germany) 96-well plate at a density of $1 \times 10^{4}$ cells followed by 2 days incubation for the initiation of spheroid formation. Spheroid were then treated with or without PGV-0, curcumin, and doxorubicin. After 96h incubation, spheroid aggregates were removed from culture plate and placed separately in single wells of 96-well plate (Iwaki). Twenty microliter of $5 \mathrm{mg} / \mathrm{mL}$ MTT solution was added to each well. The optical density (OD) of treated and untreated cells was determined at a wavelenght of $490 \mathrm{~nm}$ with a microplate reader after 4h incubation (Zanoni, et al., 2016).

\section{Effect of PGV-0, Curcumin, and Doxorubicin on Morphological 4T1 Spheroid}

Growth and morphology of the 4T1 spheroid were monitored for $96 \mathrm{~h}$ as regards changes in area, volume, and shape. The morphological properties of spheroid were observed with inverted microscope (Olympus CKX41, Olympus Corporation, Tokyo, Japan), equipped with a microscope camera (OptiLab, Phoenix, United States). Diameter of spheroid was calculated using Image Raster software, area and volume of spheroid were calculated using ImageJ software (Zanoni, et al., 2016).

\section{Cell MigrationAssay}

To asses the inhibition effect of $4 \mathrm{~T} 1$ cell migration affected by PGV-0, Curcumin, and its combination with doxorubicin, we conducted scratch wound healing. Briefly, after cells scratched, cells were treated or untreated with PGV-0, curcumin, and combination with doxorubicin. The closure area were captured under the inverted microscope (Olympus CKX41, Olympus Corporation, Tokyo, Japan) with camera (Samsung, Seoul, South Korea) at $0,18,24$, and $42 \mathrm{~h}$. The wound closure area was calculated using ImageJ software. The migration activity was quantified by percentage wound closure (Rötzer, et al., 2016; Grada, et al., 2017):

$$
\% \text { wound closure }=[(\operatorname{At} 0 \mathrm{~h}-\mathrm{At} \Delta \mathrm{h}) / \mathrm{At} 0 \mathrm{~h}] \times 100 \%
$$

AtOh $=$ The area of the wound measured immediately after scratching $(\mathrm{t}=0 \mathrm{~h})$

$A t \Delta h=$ The area of the wound measured h hours after the scratch is performed

\section{MMP-9 Protein Expression Assay}

The expression level of MMP-9 was measured by gelatin zymography. The SDS-PAGE with the gel concentration of $8 \%$ supplemented with $0.1 \%$ gelatin was used to determine the expression of MMP-9 in the culture medium. Firstly, the protein lysate was subjected to SDS-PAGE electrophoresis. After electro-phoresis running, gels were washed and incubated at room temperature. The reaction buffer was added and incubated for $24 \mathrm{~h}$ at $37^{\circ} \mathrm{C}$. Gels were stained by using Coomassie Brilliant Blue R-250 (Sigma Aldrich, Steinheim, Germany) and destained until clear bands with dark blue background appeared. The results were documented and analyzed by using ImageJ software (Hu and Beeton, 2010).

\section{Statistical Analysis}

Data were showed as mean \pm SE. One way analysis of variance (ANOVA) followed by the least significant difference (LSD) test were used for statistical analysis. P-values less than 0.01 were considered significant. 


\section{RESULTS}

\section{Effect of PGV-0 and curcumin on cell viabil- ity of monolayer $4 \mathrm{~T} 1$}

The single treatment of PGV-0 and curcumin can reduce cell viability on monolayer 4T1 cells as the dose of the treatment increases (dose-dependent manner), with $\mathrm{IC}_{50}$ values of $49 \pm 3.24 \mu \mathrm{M}$ and $12 \pm 3.15 \mu \mathrm{M}$, respectively (Figure $1 \mathrm{~A})$. Interestingly, when PGV-0 were treated against Vero cells and 3T3-L1 cells, they were proven to $100 \mu \mathrm{M}$ (Figure 1C-D). In contrast, curcumin exerted a cytotoxic effect on 3T3-L1 cells with $\mathrm{IC}_{50}$ values of $33.6 \pm 2.12 \mu \mathrm{M}$ (Figure 1D). Hence, the PGV-0 had a good selectivity as indicated by the selectivity index (SI) $\geq 2$ (Table 1 ). These data showed that PGV-0 potentially developed as a chemopreventive agent. The safety level of PGV-0 against normal cells also support this compound to be developed as co-chemotherapeutic agent. To validate these data, it is necessary to explore further PGV-0 effect on spheroid cell culture.

\section{Effects of PGV-0 and curcumin on cell viabil- ity and volume of spheroid 4T1}

In this study, a spheroid model of 4T1 cells was used as a model of triple-negative breast cancer (TNBC). The result showed that PGV-0 exhibited a cytotoxic effect to the speroid culture with $\mathrm{IC}_{50}$ values of $26 \mu \mathrm{M}$ which were not significantly different from the $\mathrm{IC}_{50}$ curcumin values of $23 \mu \mathrm{M}$ (Figure 1B). Hence, PGV-0 was able to decrease spheroid volume in dose and time dependent manners (Figure 2A). At the concentration of $25 \mu \mathrm{M}$, PGV-0 reduced the spheroid cells volume by $96 \%$ and showed a unique morphological change that was different. The decrease in volume seems to be due to the detachment process from a very compact initial structure. The morphological changes phenomena occured very quickly after $24 \mathrm{~h}$ incubation (Figure 2B), cells underwent detachment and looked to be apoptosis. Unlike the spheroid that was treated with curcumin, the volume reduction process tended to be slower because the detachment process occured slowly. This can be seen from the detachment cells around the spheroid (Figure 2B). These phenomena suggested that PGV-0 is interesting to further explore for its anti-metastatic activity and its effects when combined with doxorubicin.

\section{Effects of doxorubicin on cell viability and morphology against monolayer and spheroid 4T1}

Furthermore, doxorubicin cytotoxic assay was conducted both on monolayer and spheroid models of $4 \mathrm{~T} 1$ cells. The results showed that doxorubicin is highly cytotoxic towards monolayer and spheroid 4T1 cells with the $\mathrm{IC}_{50}$ values of $3 \mu \mathrm{M}$, respectively (Figure 3A-B). We found that at low concentration, doxorubicin (10 $\mathrm{nM}$ ) was able to induce lamellipodia formation in monolayer 4T1 cells and initiated the formation of new spheroid aggregates around the primary spheroid (Figure 3C). These phenomena are part of early initiation of metastatic. In this study, we explored the PGV-0 as a co-chemotherapeutic agent to inhibit the breast cancer metastasis.

\section{Combination of PGV-O or curcumin with} doxorubicin inhibited 4T1 cells migration

To examine the effect of PGV-0 to the initial metastatic of cancer cells we employed 4T1 cells under stressed by doxorubicin to observe the migration phenomenon. The single treatment of PGV-0 at the concentration of $25 \mu \mathrm{M}$ and $50 \mu \mathrm{M}$ showed significant migration inhibitory effects compared to the control cell (99\% confidence level) with a closure percentage value up to $51 \%$ and $53 \%$, respectively. In contrast, curcumin showed an inhibitory effect with a closure percentage value up to $61 \%$ at the concentration of $10 \mu \mathrm{M}$ (Figure 4). The single treatment of PGV-0 inhibited the migration of 4T1 breast cancer cells and suppressed doxorubicin-induced EMT on 4T1 cells. Interestingly, the combination of PGV-0 with doxorubicin showed a stronger migration inhibitory activity than the combination of curcumin with doxorubicin. The combination of PGV-0 with doxorubicin showed a closure percentage value of $38 \%$ and $41 \%$ while in the combination of curcumin with doxorubicin showed a closure percentage value of $48 \%$ and $64 \%$. 
A.

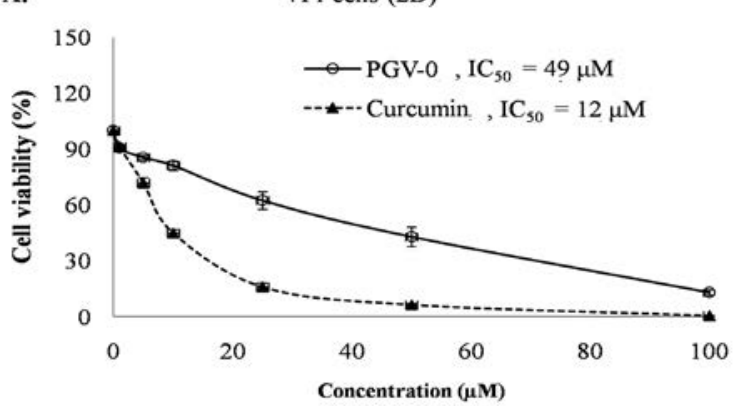

C.

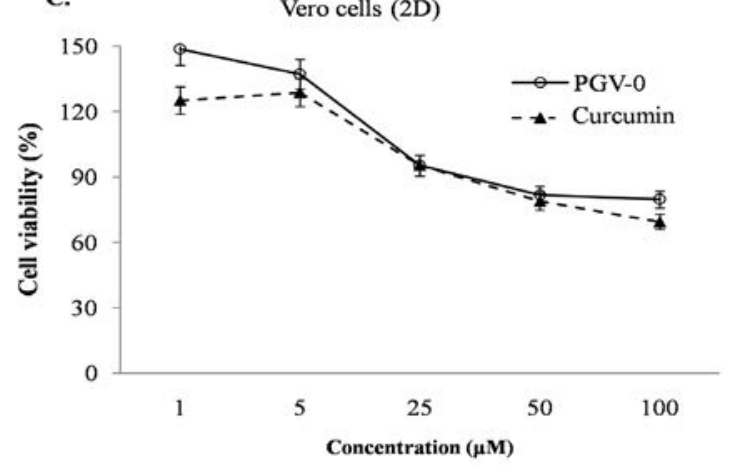

B.
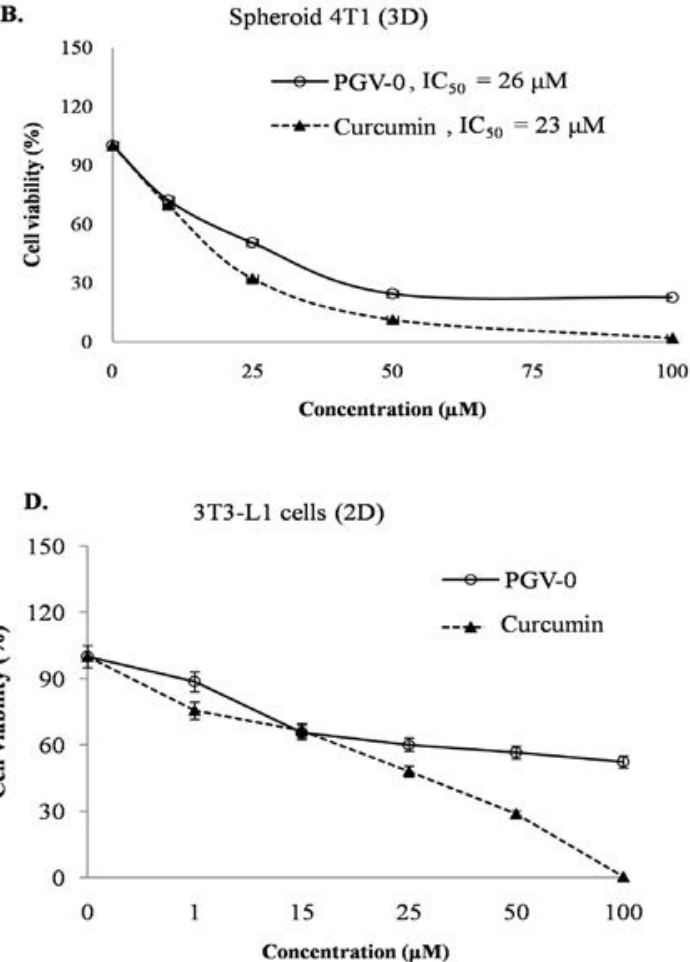

Figure 1. Cytotoxicactivity of pentagamavunone-0 (PGV-0) and curcumintoward breast cancer cells and normal cells. Cells were seeded in 96 well-plate and incubated for $24 \mathrm{~h}$ (monolayer cells) and $96 \mathrm{~h}$ (spheroid cells). Cell viability was determined by using MTT assay as described in method. A. 4T1 cells (2D); B. Spheroid 4T1 (3D); C. Vero cells (2D); D. 3T3-L1 cells. Profiles of cell viability were \pm standard error of mean (SEM) of the three independent experiment.

Combination of PGV-0 or curcumin with $\mathrm{dx}$ orubicin decreased MMP-9 expression on 4T1 cells

Further, we explored the effect of PGV0 on the MMP-9 expression in 4T1 cells under doxorubicin treatment. The results showed that a single treatment of $\mathrm{PGV}-0$ was able to reduce MMP-9 expression better than curcumin. Interestingly, after the combination of PGV-0 and doxorubicin there was found a decrease in MMP-9 expression which was more significant (Figure 5).

Table 1. Cytotoxic activities and selectivity index (SI)

\begin{tabular}{|c|c|c|c|c|c|}
\hline \multirow{2}{*}{ Sample } & \multicolumn{3}{|c|}{$I C_{50}(\mu M)$} & \multicolumn{2}{|c|}{$\mathrm{SI}$} \\
\hline & 4T1 & Vero & 3T3-L1 & (Vero) & (3T3-L1) \\
\hline PGV-0 & $49 \pm 3.24$ & $142 \pm 4.94$ & $111 \pm 2.05$ & 2.9 & 2 \\
\hline Curcumin & $12 \pm 3.15$ & $126 \pm 11.95$ & $33.6 \pm 2.12$ & 10.5 & 2 \\
\hline
\end{tabular}



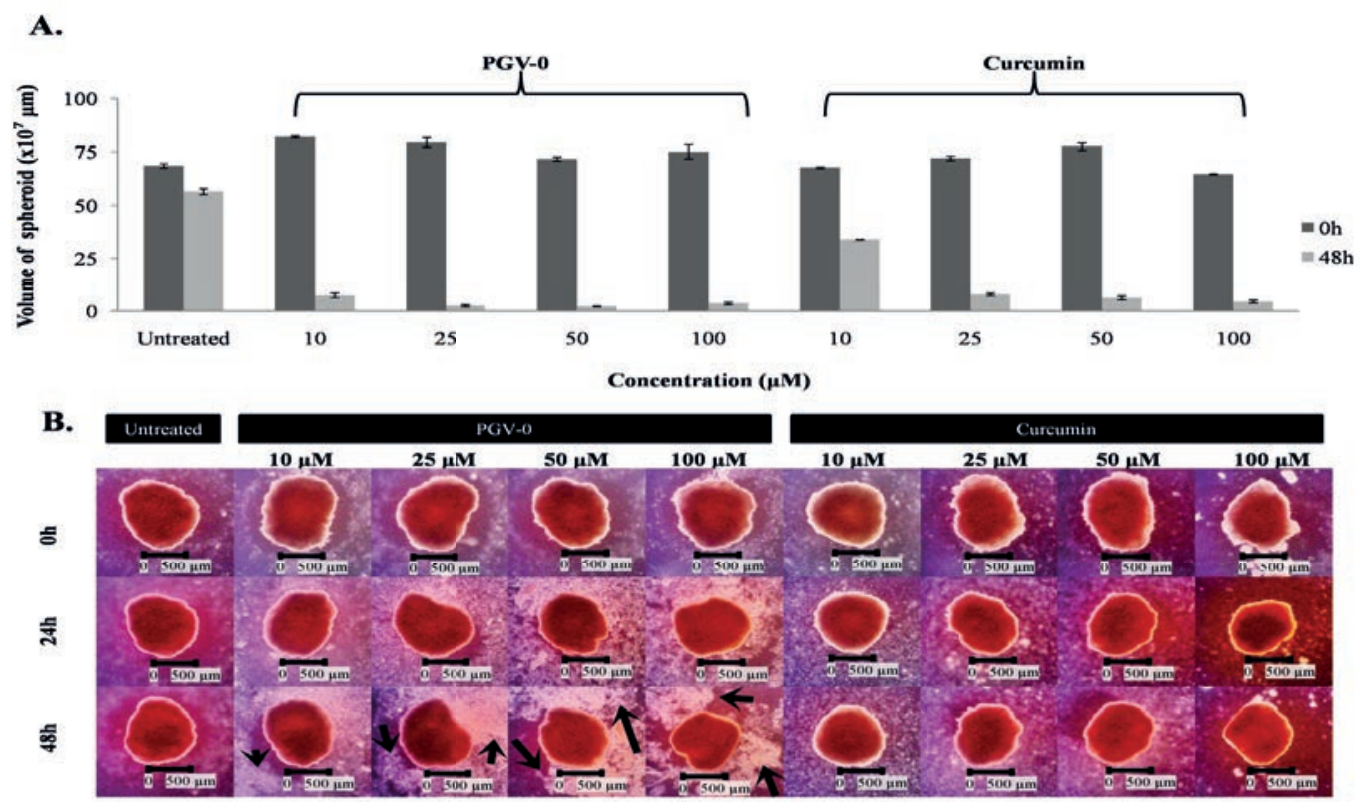

Scale bar : $500 \mu \mathrm{m}$

Figure 2. Effects of PGV-0 and curcumin on spheroid triple-negative breast cancer 4T1. Homogeneous-sized and shaped 4T1 spheroids were treated for 48h with various concentration of PGV-0 and curcumin, scale bar $=500 \mu \mathrm{m}$. A. Volume of spheroid; B. Morphology of spheroid; scale bar: $500 \mu \mathrm{m}$. The morphological feature and volume of spheroid were observed at 0, 24 and 48 hours under an inverted microscope. The arrow $(\uparrow)$ shows the spheroid undergoing a detachment process. Spheroid volume was quantified with ImageJ and data are mean of three repetition.

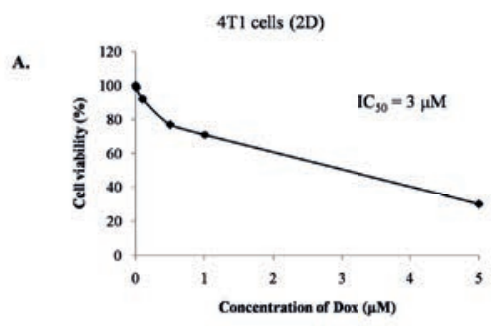

B.
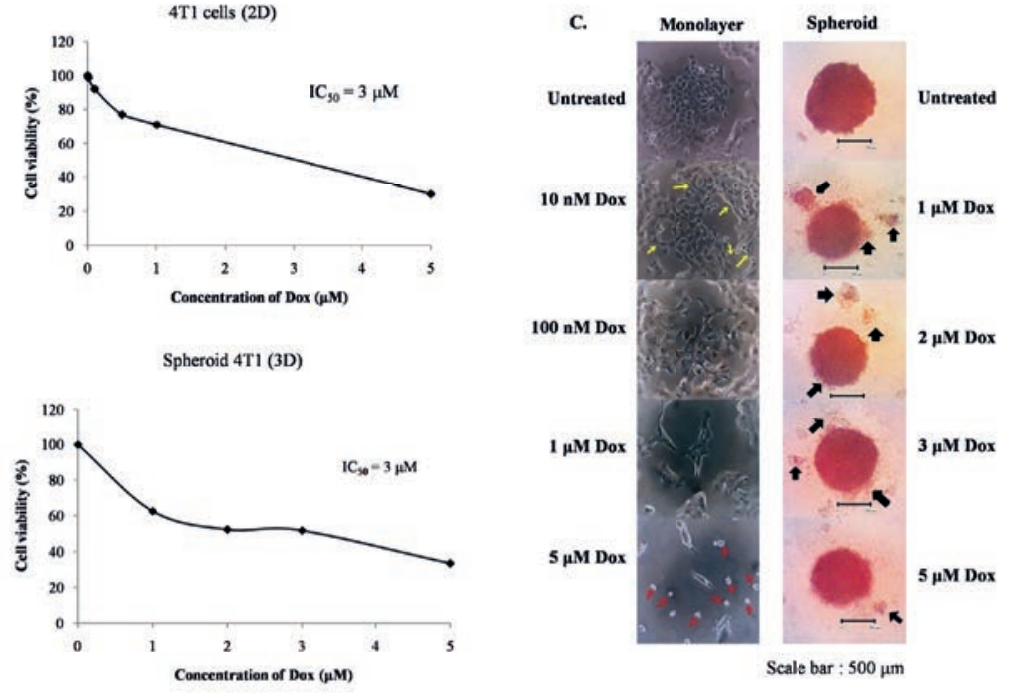

Figure 3. Cytotoxic activity of doxorubicin (Dox) in triple-negative monolayer and spheroid 4T1 cells. Cells with various concentrations were incubated with PGV-0 and curcumin for 24h (monolayer cells) and 96 hours (spheroid cells). Cell viability was obtained from by MTT treatment as described in the method. Changes in morphological feature and volume of spheroid were observed under an inverted microscope. A. Monolayer cells 4T1 (2D); B.Spheroid 4T1 (3D); C. Morphological feature of monolayer and spheroid 4T1 cells after treated, scale bar: $500 \mu \mathrm{m}$. The blackarrow $(\uparrow)$ indicates the spheroid has undergone a migration process, the yellow arrow $(\uparrow)$ indicates lamellipodia, and the red arrow $(\uparrow)$ indicates cell apoptosis. Data were \pm standard error of mean (SEM) of the three trials. 
Muflikhasari, et al., 2019

Indones. J. Cancer Chemoprevent., 10(3), 149-158
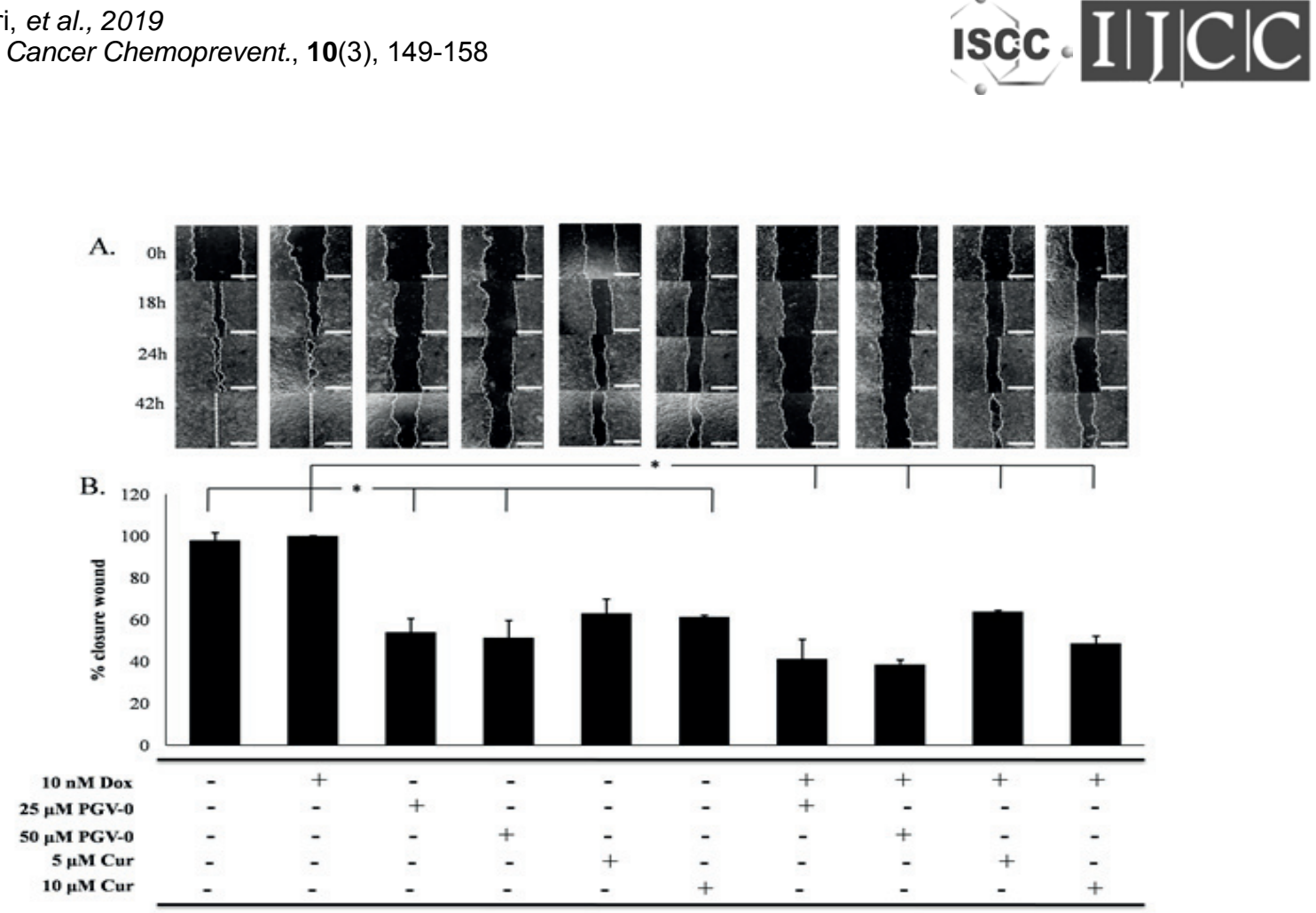

Figure 4. Effect of PGV-0 or curcumin, and its combination with doxorubicin on 4T1 cells migration. A. The morphology of the cells after scratch and treated with $10 \mathrm{nM}$ doxorubicin, PGV-0, curcumin and their combination. Observations were made after $0,18,24$ and $42 \mathrm{~h}$ of treatment under an inverted microscope with magnification of 100x, scale bar: $500 \mu \mathrm{m}$. B. The percentage of $4 \mathrm{~T} 1$ cells closure after $24 \mathrm{~h}$ of treatment. Values were means of $\%$ closure $\pm \mathrm{SD}$ from 3 independent experiments. The area of the scratch were analyzed using Image J software then \% closure was calculated in accordance with the procedures of the analysis. The asterisk ${ }^{*}$ ) indicates $p<0.01 ; n=3$. Cur: Curcumin.

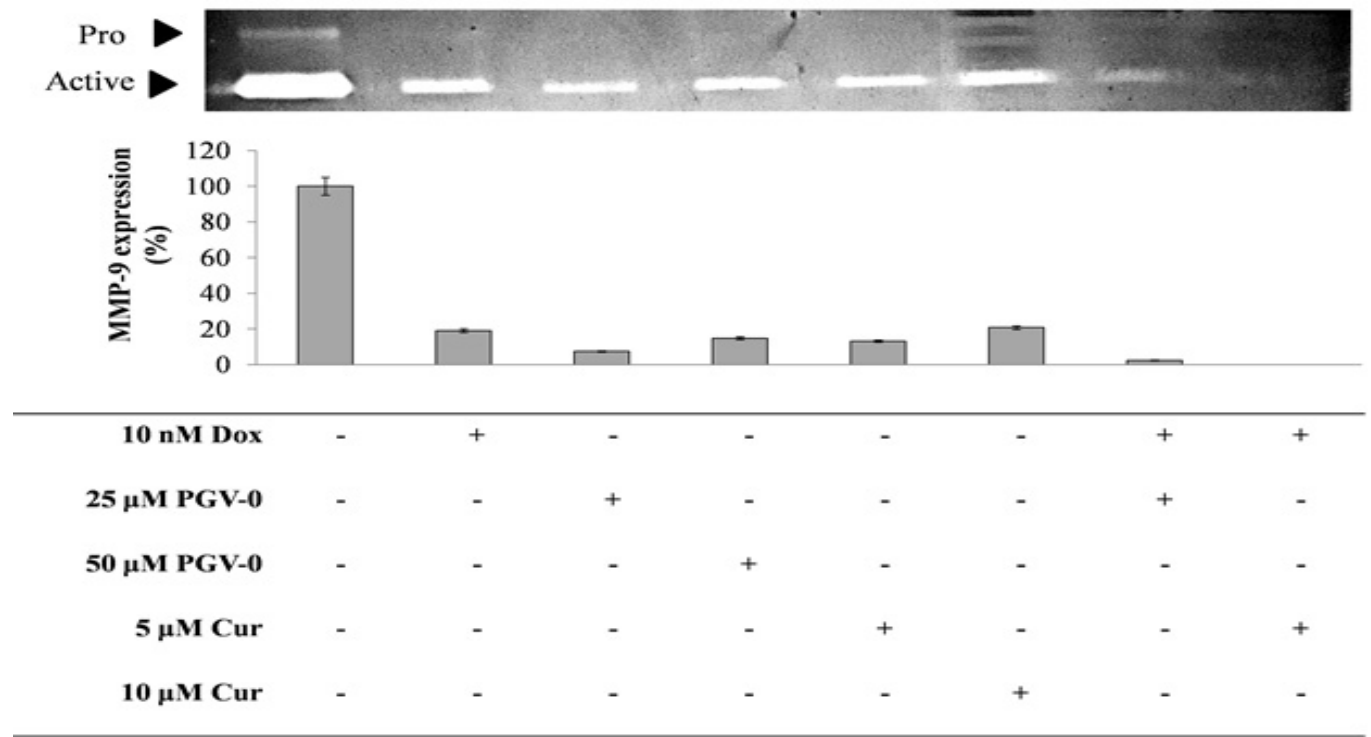

Figure 5. Effect of PGV-0 or curcumin and its combination with doxorubicin on MMP-9 expression. Cells were treated with $10 \mathrm{nM}$ doxorubicin, PGV-0, curcumin, and their combination. MMP-9 expression assay was conducted using gelatin zymography according to the method. Analysis of the results were done by using ImageJ software to measure the intensity of gelatin degradation by MMP-9 in the gel. 


\section{DISCUSSION}

The development of curcumin analog compounds is reported to be able to increase the pharmacological and stability of curcumin. Recent studies have shown that the curcumin analog PGV-1 can increase ROS levels and has anti-migratory effect in 4T1 cells (Meiyanto, et al., 2019). The PGV-0, which has a structure similar to PGV-1, is also thought to have a cytotoxic effect on $4 \mathrm{~T} 1$ breast cancer cells both in monolayer and spheroid system cultures. Following cytotoxic assay in this study, PGV-0 and curcumin performed cytotoxic effect on 4T1 monolayer with the $\mathrm{IC}_{50}$ of $49 \pm 3.24 \mu \mathrm{M}$ and $12 \pm 3.15$ $\mu \mathrm{M}$, respectively. In this regards, PGV-0 performs medium cytotoxic activity to the cancer cells. Interestingly, PGV-0 induced spheroid dissociation from the compact structure of spheroid at 24h incubation. This phenomenon indicated that the administration of PGV-0 may disrupt the cell integration that usually facilitated by protein integrin. However, the mechanism of PGV-0 towards cells separation must be explored further. Moreover, the distribution of compound on spheroid that could perform cytotoxic activity also interesting to be studied further.

PGV-0 tends to less cytotoxic effect compared to curcumin. This phenomenon might be caused by the differences in polarity of two compound resulting in differences in the process of diffusion of compound into the cells (Chen, et al., 2012; Putri, et al., 2016). The concept of developing anti-tumorigenesis agents or chemotherapeutic agents does not require a very strong cytotoxic effect, yet only require compounds that have spesific targets on cancer physiology and are able to modulate the cellular development of cancer. In addition, compounds used as chmopreventive agents actually avoid compounds that have very strong cytotoxic to minimize the presence of non-selective toxicity effects. An extract or compound is not selective if the SI value $<2$. PGV-0 have good selectivity with SI values of $\geq 2$ (compared to normal cells Vero and 3T3-L1).
Doxorubicin is an important chemotherapeutic agent and the most widely used in cancer therapy, including breast cancers. Doxorubicin showed cytotoxic effect on monolayer and spheroid $4 \mathrm{~T} 1$ cells with the same $\mathrm{IC}_{50}$ value, which is about $3 \mu \mathrm{M}$. On the morphological observations of the spheroid model, it was known that there were no morphological changes in high-dose of doxorubicin treatment. This phenomenon showed the resistance effect of spheroid against the high concentration of doxorubicin.

Doxorubicin also demonstrate a stress inducing agent to cancer cells by generating ROS intracellular by which cancer cells exhibit malignant characteristic, such as lamellipodia formation and cell migration (Amalina, et al., 2017; Yang, et al., 2017). Interestingly, PGV-0 in combination with doxorubicin was able to inhibit migration more significantly. Moreover, PGV-0 and its combination with doxorubicin suppressed MMP-9 expression better than curcumin. All of these data suggested that PGV-0 increase the cellular stress leading to the suppression of the cell growth and may induce cell death on 4T1 cells. These phenomena are suitable for co-chemotherapeutic application that enhance the effectiveness of chemotherapeutic agents and decrease the adverse effects.

\section{CONCLUSION}

The curcumin analogue PGV-0 inhibited cell growth, cell migration and suppressed MMP-9 expression in stress condition of 4T1 cells. Therefore, PGV-0 has the potency to be developed as co-chemotherapeutic agent in metastatic cancer of triple-negative breast cancer.

\section{ACKNOWLEDGMENT}

The authors are grateful to Cancer Chemoprevention Research Center, Faculty of Pharmacy, Universitas Gadjah Mada for providing PGV-0 and curcumin. 


\section{REFERENCES}

Amalina, N.D., Nurhayati, I.P. and Meiyanto, E., 2017, Doxorubicin Induces Lamellipodia Formation and Cell Migration, Indones. J. Cancer Chemoprevention, 8, 61-67. Chen, G. , Chen, Y., Yang, N. , Zhu, X., Sun, L. and Li, G., 2012, Interaction between curcumin and mimetic biomembrane, Sci. China Life Sci. , 55, 527-532.

Courtneidge, S.A., 2012, Cell migration and invasion in human disease: the Tks adaptor proteins, Portland Press Limited.

Cui, X., Hartanto, Y. and Zhang, H., 2017. Advances in multicellular spheroids formation, J. R. Soc. Interface, 14.

Glasauer, A., Chandel, N.S., 2014. Targeting antioxidants for cancer therapy, Biochem. Pharmacol., 92, 90-101. Grada, A., Otero-Vinas, M., Prieto-Castrillo, F., Obagi, Z., Falanga, V., 2017, Research Techniques Made Simple: Analysis of Collective Cell Migration Using the Wound Healing Assay, J. Invest. Dermatol., 137, e11-e16.

Hermawan, A., Fitriasari, A., Junedi, S., Ikawati, M., Haryanti, S., Widaryanti, B., Da'i, M. and Meiyanto, E., 2011, PGV-0 and PGV-1 Increased Apoptosis Induction of Doxorubicin on MCF-7 Breast Cancer Cells, Pharmacon, 12(2), 55-59.

$\mathrm{Hu}$, X. and Beeton, C., 2010, Detection of functional matrix metalloproteinases by zymography, JoVE J. Vis. Exp. e2445.

Ikawati, M. and Septisetyani, E.P., 2018, Pentagamavunone-0 (PGV-0), a Curcumin Analog, Enhances Cytotoxicity of 5-Fluorouracil and Modulates Cell Cycle in WiDr Colon Cancer Cells, Indones. J . Cancer Chemoprevention, 9(1), 23-31.

Kleiner Jr, D.E. and Stetler-Stevenson, W.G., 1993, Structural biochemistry and activation of matrix metalloproteases, Curr. Opin. Cell Biol., 5, 891-897. Larasati, Y.A., Yoneda-Kato, N., Nakamae, I., Yokoyama, T., Meiyanto, E. and Kato, J., 2018, Curcumin targets multiple enzymes in- volved in the ROS metabolic pathway to suppress tumor cell growth, Sci. Rep. 8, 1-13. Meiyanto, E., Margono, S.A. and Da'i, M., 2003, Antiproliferative effect of PGV-0 (a curcumin analogue) against HeLa cells, Gama Sains, 5, 200-206. Meiyanto, E., Putri, D.D.P., Susidarti, R.A., Murwanti, R., Sardjiman, S., Fitriasari, A., Husnaa, U., Purnomo, H. and Kawaichi, M., 2014, Curcumin and its Analogues (PGV-0 and PGV-1) Enhance Sensitivity of Resistant MCF-7 Cells to Doxorubicin through Inhibition of HER2 and NF-kB Activation, Asian Pac. J. Cancer Prev., 15, 179-184. Meiyanto, E., Putri, H., Larasati, Y.A., Utomo, R.Y., Jenie, R.I., Ikawati, M., Lestari, B., YonedaKato, N., Nakamae, I. and Kawaichi, M., 2019. Anti-proliferative and Anti-metastatic Potential of Curcumin Analogue, Pentagamavunon-1 (PGV-1), Toward Highly Metastatic Breast Cancer Cells in Correlation with ROS Generation, Advanced Pharmaceutical Bulletin, 9(3), 445-452.

Meiyanto, E., Septisetyani, E.P., Larasati, Y.A. and Kawaichi, M., 2018, Curcumin Analog Pentagamavunon-1 (PGV-1) Sensitizes Widr Cells to 5-Fluorouracil through Inhibition of NF-kB Activation, Asian Pac. J. Cancer Prev., 19(1), 49-56.

Mosmann, T., 1983, Rapid colorimetric assay for cellular growth and survival: application to proliferation and cytotoxicity assays, J. Immunol. Methods, 65, 55-63.

Nunes, A.S., Barros, A.S., Costa, E.C., Moreira, A.F. and Correia, I.J., 2019, 3D tumor spheroids as in vitro models to mimic in vivo human solid tumors resistance to therapeutic drugs: NUNES ET AL, Biotechnol. Bioeng., 116, 206-226.

Putri, H., Jenie, R.I., Handayani, S., Kastian, R.F. and Meiyanto, E., 2016. Combination of Potassium Pentagamavunon-0 and Doxorubicin Induces Apoptosis and Cell Cycle Arrest and Inhibits Metastasis in Breast Cancer Cells, Asian Pac J Cancer Prev., 17, 2683-2688.

Rötzer, V., Hartlieb, E., Winkler, J., Walter, E., Schlipp, A., Sardy, M., Spindler, V. and Waschke, J., 2016, Desmoglein 3-Dependent Signaling 
Indonesian Journal of Cancer Chemoprevention, October 2019

ISSN: 2088-0197

e-ISSN: $2355-8989$

Regulates Keratinocyte Migration and Wound Healing, J. Invest. Dermatol., 136, 301-310.

Yang, J., Guo, W., Wang, L., Yu, L., Mei, H., Fang, S., Chen, A., Liu, Y., Xia, K. and Liu, G., 2017, Notch signaling is important for epithelial-mesenchymal transition induced by low concentrations of doxorubicin in osteosar- coma cell lines, Oncol. Lett., 13, 2260-2268. Zanoni, M., Piccinini, F., Arienti, C., Zamagni, A., Santi, S., Polico, R., Bevilacqua, A. and Tesei, A., 2016, 3D tumor spheroid models for in vitro therapeutic screening: a systematic approach to enhance the biological relevance of data obtained, Sci. Rep. 6, 19103. 